\title{
Globalization, co-operation costs, and wage inequalities
}

\author{
By Edward Anderson*, Paul J. G. Tang†, and Adrian Woodł
}

${ }^{\star}$ Overseas Development Institute, London

$\uparrow$ Ministry of Economic Affairs, The Netherlands

\$Queen Elizabeth House, University of Oxford, Mansfield Road, Oxford OX1 3TB; e-mail: adrian.wood@qeh.ox.ac.uk

\begin{abstract}
The falling cost of international business travel and communication motivates highlyskilled workers who live in developed countries to spend more of their time co-operating with less-skilled workers in developing countries. This tends to narrow the gap between developed and developing countries in the wages of less-skilled workers, but to widen the wage gap within developed countries between highly-skilled and less-skilled workers. The paper formalizes this mechanism and tests it on data for the United States and developing countries. The two effects on wage inequalities of greater co-operation of highly-skilled workers with workers in developing countries both seem quantitatively important.
\end{abstract}

JEL classifications: F16, O19, O33.

\section{Introduction}

The debate about globalization and wage inequalities continues to attract attention. The first phase of the debate focused on the fall in the wages of Northern unskilled workers, relative to Northern skilled workers, which in principle could be explained by Heckscher-Ohlin ( $\mathrm{H}-\mathrm{O})$ theory as a result of falling barriers to trade between the North and the South (e.g. Leamer, 1993; Wood, 1994), although the magnitude of this effect in practice was the subject of wide disagreement (e.g. Cline, 1997). A second phase of the debate was set off by the finding that increased openness had widened wage gaps between skilled and unskilled workers in some developing, as well as developed, countries, which could not be explained in the standard H-O model (Robbins, 1996; Feenstra and Hanson, 1996; Wood, 1997; Anderson, 2005).

What motivates this paper, though, are two other changes in wage inequalities which cannot be explained by the $\mathrm{H}-\mathrm{O}$ mechanism, either. The first is that wage inequality in the North has increased not only in the lower ranges of the skill distribution, but also right at the top, where a small group of highly-paid workers has pulled rapidly, persistently and conspicuously away from the rest 
(e.g. Bernstein and Mishel, 1997). The second is that in the Southern countries which have integrated most successfully into the world economy, the outcome has been not, as the $\mathrm{H}-\mathrm{O}$ model would predict, absolute gains for some skill groups and absolute losses for others, but rather that the wages of all groups have risen, even though some have gained more than others (e.g. World Bank, 1993, 2003).

These two changes in wage inequalities might be related neither to one another nor to globalization - the wage gains at the top in the North could be due to new technology, for example, and those of workers in successful Southern countries to capital accumulation. Our hypothesis, however, is that the two are related and are results of globalization, acting through a mechanism different from the standard $\mathrm{H}-\mathrm{O}$ one. The $\mathrm{H}-\mathrm{O}$ mechanism is driven by the falling cost of moving goods around the world, while these changes-we suggest-are driven by the falling cost of moving know-how around the world. In particular, cheaper travel and telecommunication have enabled highly-skilled workers who live in developed countries to co-operate far more extensively in production with workers in developing countries, through frequent short visits bridged by phone calls and e-mails. This has raised the wages of highly-skilled workers, by expanding the market for their services, and thus could explain the rise in inequality at the top of the Northern wage distribution. Improved access to the services of highly-skilled Northern workers has also raised the productivity of all workers in Southern countries, and thus could explain the across-the-board rises in wages in those countries.

\subsection{Elaboration of the hypothesis}

In later sections of the paper, we formalize this mechanism in a simple model and subject it to empirical testing. In the rest of this introduction, we discuss the mechanism more intuitively and explain how our model relates to various other models.

Our 'highly-skilled' workers are a small subset of the much broader category usually identified as 'skilled' on the basis of their education or training. They are, rather, an elite of managers, entrepreneurs, designers, engineers, and other business professionals, who often have high levels of education but whose value to their employers stems mainly from their creativity, experience and connections, acquired fortuitously from their genes, families, and careers. They contribute to production partly by increasing the quantity of output, but mainly by improving its quality and marketability. Specifically, what highly-skilled workers know is how to produce state-of-the-art goods and services and to sell them in any market in the world against competition from other such goods and services.

Some of these goods and services are skill-intensive, in the sense that their production requires intensive use of other sorts of skilled workerspharmaceuticals and software, for example. Other state-of-the-art goods, however, 
are not-sports shoes, computer assembly, up-market beach resorts, and off-season fruits and vegetables, for example. ${ }^{1}$ For analysing some aspects of globalization and wage inequality, this variation in skill intensity is important (for $\mathrm{H}-\mathrm{O}$ reasons), but to provide a clear description of our mechanism, we will abstract from it and focus on the distinction between all state-of-the-art items and the lower-quality items which account for much of the South's production and consumption. Correspondingly, we abstract from all differences in levels of skill among workers other than the distinction between our small highly-skilled elite and the rest, to whom we will refer as 'less-skilled' workers (acknowledging, of course, that this dividing line, like those between other skill groups, is in practice somewhat arbitrary).

Most highly-skilled workers live in developed countries, because of externalities-economies of clustering - of two sorts. One is that frequent contact among such workers, face-to-face as well as by telecommunication, is vital for the acquisition and maintenance of their skills. The other is that many of the amenities valued by highly-skilled workers and their families can be supplied only by clusters of highly-skilled workers. These forces explain the limited scale of long-term expatriate employment in the South, both historically and currently: the skills of the workers atrophy and become obsolete as a result of isolation; and employers have to pay them more to compensate for the loss of Northern amenities. The same forces explain why few highly-skilled workers choose to migrate to the South, despite what might seem to be the prospect of higher earnings there because of their greater scarcity.

Even though they choose to reside in the North, highly-skilled workers have the option of business travel to the South-intermittent and brief visits that are planned, followed up and supplemented by telecommunication-which can enable them to render services there. But it is more expensive and less efficient to provide services abroad than at the worker's Northern base. This is partly because of the direct expenses of travel and telecommunication (air fares, hotel bills, and charges for phone calls, faxes, and e-mail messages). These direct costs, however, are dwarfed by the opportunity costs of time wasted both while travelling and while working in the South (for example, hanging about in airports and dealing with problems that arise from differences in institutions, culture, and language). Similarly, insofar as the co-operation is by telecommunication rather than by travel, the main cost is the extra time

\footnotetext{
${ }^{1}$ The role of highly-skilled Northern workers in such sectors in Southern countries is well-documented in case studies. Hobday (1995) studies the evolution of the East Asian electronics industry. Gereffi (1999) reviews the contribution of technical and marketing expertise by Northern buyers to the production of apparel for export in Southern countries. Schmitz and Knorringa (2000) provide a similar analysis of footwear. Dolan and Humphrey (2000) describe how African exporters of fresh vegetables are guided in crop selection, growing techniques, packaging and marketing by UK supermarkets and importers.
} 
involved in distance-work, as compared with doing the same thing on the spot. Highly-skilled workers are thus a semi-mobile factor of production: their services can be moved from one country to another, but only by incurring what we shall call 'co-operation costs'.

Business travel by highly-skilled workers has a long history-think, for example, of Mozart touring round the courts of Europe-but its scale has risen over time and increased rapidly in the past few decades (for example, a more than three-fold increase between 1980 and 2000 in the number of international business trips by UK residents; Anderson, 2004). The reason, of course, is great improvements in the quality and cost of transport and telecommunications, which have made business travel much easier and cheaper, not least in terms of wasted time. Co-operation costs have been reduced also by changes in policies and institutions in both developed and developing countries, which have made it quicker and more efficient to transact business abroad. These improvements have been widely noted as a cause of increased international economic integration (e.g. Harris, 1995; World Bank, 2003).

Nonetheless, the excess costs of working abroad remain substantial, so to explain why it happens one must identify an offsetting gain. There are many possible reasons why highly-skilled workers might find it worth their while to render services in the South. But the reason on which we shall focus, which is of particular relevance to the impact of globalization on wage inequalities, is that less-skilled workers cost less in the South than they do in the North. The total cost of production for certain activities may thus be lower in the South, even though highly-skilled workers have to be paid more than in the North to induce them to participate. The most obvious examples are goods produced in the South for export to the North, but the same point applies to the production of goods and services for sale in the Southern home market-even in a poor country, there is some demand for state-of-the art items, and this rises steadily as the country becomes richer.

Falling co-operation costs increase the number of activities in the South in which it is worth paying highly-skilled workers from the North to participate. This raises the demand for the services of highly-skilled workers, and so tends to pull up their wages. However, it tends to lower the wages of less-skilled Northern workers, by eroding their privileged access to production with highly-skilled workers (which enables them to earn more than Southern workers with comparable levels of skill). Conversely, it also tends to raise the wages of Southern workers (all of whom we assume for simplicity to be less-skilled). The effect is thus to reduce wage inequality between Southern and Northern less-skilled workers, but to increase inequality in the North between highly-skilled and less-skilled workers. This occurs fundamentally because know-how or tacit knowledge, unlike some other sorts of knowledge, is not a public good: it is excludable (less-skilled workers benefit from it only if highly-skilled workers choose to co-operate with them) and it is rivalrous (more of it being deployed in the South is likely to mean less of it being deployed in the North). 


\subsection{Comparison with other models}

Our hypothesis and the model in which we formalize it in later sections are related to, but distinct from, various other important contributions to economic analysis. The magnification of the wages of highly-skilled people by access to a wider market was modelled in the seminal paper of Rosen (1981), later elaborated by Frank and Cook (1995), and earlier articulated, as Rosen points out, by Marshall, who wrote of the rise in income inequality caused by 'the development of new facilities for communication, by which men... are enabled to apply their constructive or speculative genius to undertakings... extending over a wider area than ever before' (1920, book VI, ch.XII, § 11). Our explanation of the rise in the wages of the highly-skilled is essentially similar, but we introduce a North-South dimension and explain how the effects on the wages of less-skilled workers vary between the North and the South.

The North-South dimension of our model is similar in some respects to recent analyses of transnational companies (TNCs) which treat them as channels through which know-how is transferred from one country to another, a process which clearly involves a lot of travel and telecommunication by highly-skilled workers (e.g. Markusen, 2001). Our model, however, is not limited to any one institutional form of business organization. The involvement of highly-skilled workers in Southern production can and does occur not only within TNCs but also in the framework of long-term supply contracts and other arms-length business relationships. ${ }^{2}$ Our model also highlights the costs of transferring know-how from one country to another, which are overlooked in recent models of TNCs (as noted by Harhoff, 1999).

Another related literature with a North-South dimension is that on the fragmentation of production-splitting it up into stages of differing factor intensity, which can be located more efficiently in different countries-and on the role of business services in linking the fragments of international production networks (e.g. Jones and Kierzkowski, 1990; and the papers in Arndt and Kierzkowski, 2001). There are some clear affinities with our model, since we too stress the role of highly-skilled workers in cross-border quality control and co-operation-and in this regard there are affinities also with recent analyses of international business networks (e.g. Rauch and Casella, 2003). However, our model is not limited to fragmented production or outsourcing: it applies to North-South trade in parts and components, but also to integrated production of goods and services in both regions, either for export or for domestic sale.

At a more formal level, there is a similarity between our model and another class of North-South models in which all capital is owned by Northern residents but can be shifted from the North to the more capital-scarce South, which raises the returns to capital and the wages of Southern workers, but lowers the wages of

\footnotetext{
${ }^{2}$ As is illustrated by the evidence on apparel, footwear and fresh vegetables cited in footnote 1.
} 
Northern workers (e.g. Sachs and Shatz, 1996). These distributional outcomes, resulting from the North-South shift of a semi-mobile factor, are essentially the same as in our model. The difference, of course, is that in our model it is highly-skilled labour rather than capital which is the semi-mobile factor, and that we have a more fully specified explanation of what induces it to shift from the North to the South.

A further difference between our model and the other North-South models mentioned above is the distinction we make between state-of-the-art and backward goods. In this respect our model is related to that of Murphy and Shleifer (1997), which revolves around differences in the quality of goods produced in countries at different levels of development. It has a more general affinity, too, with the many studies which emphasize technological dualism within developing countries. It also bears a resemblance to product cycle models such as Krugman (1979), in which Northern workers earn more than Southern workers because new goods can be produced only in the North. A difference, though, is that in Krugman's model there is just one class of Northern workers, whereas in our model the North's monopoly of the ability to produce new goods is linked to its supply of highly-skilled workers.

The distinction between advanced and backward goods also differentiates our analysis from the standard H-O model in which it is assumed that the South could produce all goods in autarky (an assumption often criticized by development economists). In our model, Southern production of state-of-the-art goods depends on the expertise of highly-skilled workers from the North. Moreover, in the standard $\mathrm{H}-\mathrm{O}$ model, changes in wage inequalities are driven by reduction of the cost of moving goods between North and South, whereas the driver in our model is reduction of the costs of moving know-how.

Our model is similar in some ways to the specific-factors trade model, in that highly-skilled workers are needed for the production only of state-of-the-art goods, while other sorts of workers are needed in both sectors and can move freely between them. Some of its results also resemble those of a specific-factors model: for example, a rise in the relative world price of state-of-the-art goods raises the wages of highly-skilled workers but has mixed effects on the wages of other workers. ${ }^{3}$ In the standard specific-factors model, however, factors are immobile between countries, whereas we allow a specific factor (highly-skilled labour) to be mobile - at a cost-between the North and the South, and we focus on the consequences for wages of changes in the cost of its international mobility.

\footnotetext{
${ }^{3}$ Tending to raise them in the North and lower them in the South. The endogeneity of world commodity prices in our model-the North and the South are not 'small countries'-complicates comparison with results from standard specific-factors models (e.g. Markusen et al., 1995, pp. 127-41) which permit (a) changes of country endowments at constant commodity prices and (b) exogenous changes in world prices.
} 
In the next two sections of the paper, we show how the mechanism discussed above in general terms can be formalized algebraically (and illustrated with a diagram). Section 2 sets out a model of the determination of wages at a given level of co-operation costs, which is then used in Section 3 to analyse the effects of falling co-operation costs on wage inequalities. The following two sections explore the mechanism empirically. Section 4 examines the effects of increasing international business travel on wage inequality within the North, using data from the United States. Section 5 examines the effects of co-operation costs on wage inequality between North and South, using data on a cross-section of countries. Section 6 concludes.

\section{Equilibrium with given co-operation costs}

There are two countries, North $(\mathrm{N})$ and South (S), and two skill categories of workers, both in fixed supply: highly-skilled workers, whose number is denoted by $\mathrm{K}$ (for know-how); and other workers, whose number is denoted by $\mathrm{L}$ (for labour). L-workers are divided in fixed proportions between the North and the South,

$$
L=L_{N}+L_{S}
$$

and can work only in the countries where they live. All K-workers live (and consume) in the North, but can work both in the North and in the South. $\mathrm{K}$-work in the South entails co-operation costs, consisting of wasted K-worker time, which is a fraction $t(\geq 0)$ of effective working time (the 'iceberg' principle), so that

$$
K=K_{N}+(1+t) K_{S}
$$

where $K_{S}$ is effective working time in the South. In this section, we treat the value of $t$ (which stands for travel and telecommunication costs) as a parameter.

There are two goods, a state-of-the-art one (labelled A for advanced) and a lower-quality one (labelled B for basic). Production of the B-good requires only L-workers, with a technology such that one unit of L-work produces one unit of B-output. Production of the A-good requires K-workers as well as L-workers, with a constant-returns-to-scale technology, $Q=L f(k)$, where $k$ is $K / L$ and $f^{\prime}>0, f^{\prime \prime}<0$. As in a specific-factors model, K-workers are used in only one sector, while L-workers are used in both sectors and mobile between them.

Both goods can be traded between the two countries. In order to isolate the effects of co-operation costs, we assume transport costs (and other barriers to trade) to be zero, so that the prices of the two goods, $p_{A}$ and $p_{B}$, are the same in both countries. 


\subsection{Alternative equilibria}

Our analysis will focus on one specific type of equilibrium, in which the North is completely specialized in production of the A-good, while the South produces both the A-good and the B-good. This type of equilibrium seems consistent with the world as we observe it today-with North-based experts overseeing enclaves of modern production in a largely traditional South - but the structure of the model as outlined above could permit other types of equilibria, which merit brief consideration here (a fuller technical exposition is available on request).

With all K-workers living in the North, the combination of positive co-operation costs and zero transport costs implies that any equilibrium must involve complete specialization in at least one country. For if co-operation costs are positive, K-work in the South (needed for it to produce the A-good) must cost more than in the North, and hence both countries could not profitably produce both goods at the same prices.

In one alternative equilibrium, the South would be specialized in production of the B-good, while the North produced both goods (corresponding perhaps to an earlier phase of history in which modernization was in progress in the North and had not started in the South). What puts the world into our type of equilibrium rather than this symmetrical alternative is a combination of three things: a North which is small relative to the South (in terms of its stock of L-workers); a strong consumer preference for the A-good over the B-good; and a relatively large global supply of K-workers, compared to L-workers (which tends to attract L-workers into the A-sector by making them more productive there). ${ }^{4}$ All three of these things make it more likely that the whole of the North's production capacity will be used to meet the world's demand for the A-good, as in the case on which we focus.

Even if, for these reasons, the North is specialized in A-production, the South need not produce both sorts of goods, as it does in our case. The level of co-operation costs, $t$, might be too high for Northern K-workers to find it worthwhile to provide any services in the South-yielding an equilibrium in which each country was specialized in one of the two goods. For work in the South to be attractive to K-workers, putting the world into our type of equilibrium rather than this fully specialized alternative, the gap in wages between Northern and Southern L-workers must be big enough to outweigh the costs of co-operation. This gap is made bigger by the same three things as in the previous paragraph. Both a larger supply of K-workers and a smaller Northern labour force tend to

\footnotetext{
${ }^{4} \mathrm{~A}$ larger global supply of K-workers relative to L-workers also pulls in the other direction by increasing the supply of the A-good and thus reducing its relative price, which tends to makes the A-sector less attractive to L-workers by lowering their marginal revenue product there. However, this contrary effect will be dominated by the effect mentioned in the text if, as is argued later in this paper, the elasticity of substitution in consumption between A- and B-goods is larger than the elasticity of substitution in A-production between $\mathrm{K}$ - and L-workers.
} 
raise the wages of Northern L-workers. ${ }^{5}$ Stronger consumer preferences for the A-good tend to raise its relative price, and hence to lower the wages of Southern L-workers (which are linked to the price of the B-good). At present, the North-South wage gap is apparently big enough to make co-operation attractive to K-workers, permitting the South to produce both goods. Thus in our type of equilibrium, world output of the B-good, with its labour-only production technology, is simply

$$
Q_{B}=L_{S}-L_{A S}
$$

where $L_{A S}$ is the part of the Southern labour force that works in the A-sector. World output of the A-good is

$$
Q_{A}=L_{N} f\left(k_{N}\right)+L_{A S} f\left(k_{S}\right)
$$

where $k_{N}=K_{N} / L_{N}$ and $k_{S}=K_{S} / L_{A S}$.

\subsection{Determination of wages}

Product and labour markets are assumed to be perfectly competitive, so that the wages of all categories of workers are equal to their marginal value products. The wage of highly-skilled workers, $w_{N}^{K}$, relative to that of other Northern workers, $w_{N}^{L}$, is thus

$$
\frac{w_{N}^{K}}{w_{N}^{L}}=\frac{f^{\prime}\left(k_{N}\right)}{f\left(k_{N}\right)-f^{\prime}\left(k_{N}\right) k_{N}}
$$

where $f^{\prime}\left(k_{N}\right)$ is the marginal physical product of K-workers and $f\left(k_{N}\right)-f^{\prime}\left(k_{N}\right) k_{N}$ that of Northern L-workers. This wage ratio, which we assume always to be greater than unity, is decreasing in $k_{N}$ (because $f^{\prime \prime}<0$ ), and hence, since $L_{N}$ is given, in $K_{N}$. Greater concentration of K-work in the North reduces wage inequality within the North by making K-workers less scarce there, relative to L-workers.

The wage of Northern L-workers relative to that of Southern L-workers, $w_{S}^{L}$, is also equal to the ratio of the marginal contributions of these two groups to A-production

$$
\frac{w_{N}^{L}}{w_{S}^{L}}=\frac{f\left(k_{N}\right)-f^{\prime}\left(k_{N}\right) k_{N}}{f\left(k_{S}\right)-f^{\prime}\left(k_{S}\right) k_{S}}
$$

\footnotetext{
${ }^{5} \mathrm{~A}$ larger supply of $\mathrm{K}$-workers also pulls in the other direction by lowering the relative price of the A-good, but on the assumptions about elasticities mentioned in footnote 4 , its net effect is to widen the wage gap.
} 
which depends on the sizes of $k_{N}$ and of $k_{S}$. In particular, if $k_{N}>k_{S}$, this wage ratio will be greater than unity (that is, Northern L-workers will earn more than Southern L-workers). This is always the case in the type of equilibrium on which we focus.

Relative wages in our model thus depend proximately on $k_{N}$ and $k_{S}$, which in turn are determined, together with two other variables (Southern employment in the A-sector, $L_{A S}$, and the relative goods price, $p_{A} / p_{B}$ ), by a set of four equations. The first,

$$
f^{\prime}\left(k_{N}\right)=\frac{1}{1+t} f^{\prime}\left(k_{S}\right)
$$

is an arbitrage condition for K-workers, whose wage in the North (the left-hand side) must in equilibrium be equal to the wage they can earn in the South, net of wasted time. The second equation,

$$
p_{A}\left[f\left(k_{S}\right)-f^{\prime}\left(k_{S}\right) k_{S}\right]=p_{B},
$$

is an arbitrage condition for Southern L-workers, who are mobile across sectors and so in equilibrium must earn the same wage in A-production (the left-hand side) as in B-production (the right-hand side, which is simply $p_{B}$ because each unit of labour produces one unit of output). There is thus a fixed, inverse, relationship between the relative price of the two goods and the value of $k_{S}$. If $p_{A} / p_{B}$ remains constant, so must $k_{S}$, and a fall (say) in $p_{A} / p_{B}$ would require a rise in $k_{S}$, to increase the marginal physical productivity of A-work relative to B-work. The third equation is the full-employment condition for highly-skilled labour,

$$
K=K_{N}+(1+t) K_{S}=L_{N} k_{N}+(1+t) L_{A S} k_{S},
$$

and the fourth equation is a demand function. For simplicity, we assume all workers to have identical homothetic preferences and that, given world (North plus South) outputs of the two goods, $Q_{A}$ and $Q_{B}$, their relative price is determined by

$$
\frac{p_{A}}{p_{B}}=q\left[\frac{Q_{A}}{Q_{B}}\right]^{-1 / \varepsilon}
$$

where $\varepsilon$ is a constant substitution elasticity. In reality, the demand for state-of-theart goods is income-elastic, so that the lower-quality B-good is likely to be consumed more in the South and by L-workers than in the North and by K-workers. To introduce income elasticity into the demand function would unduly complicate the model, but a simpler modification along these lines would be to assume that the B-good is consumed only in the South. 


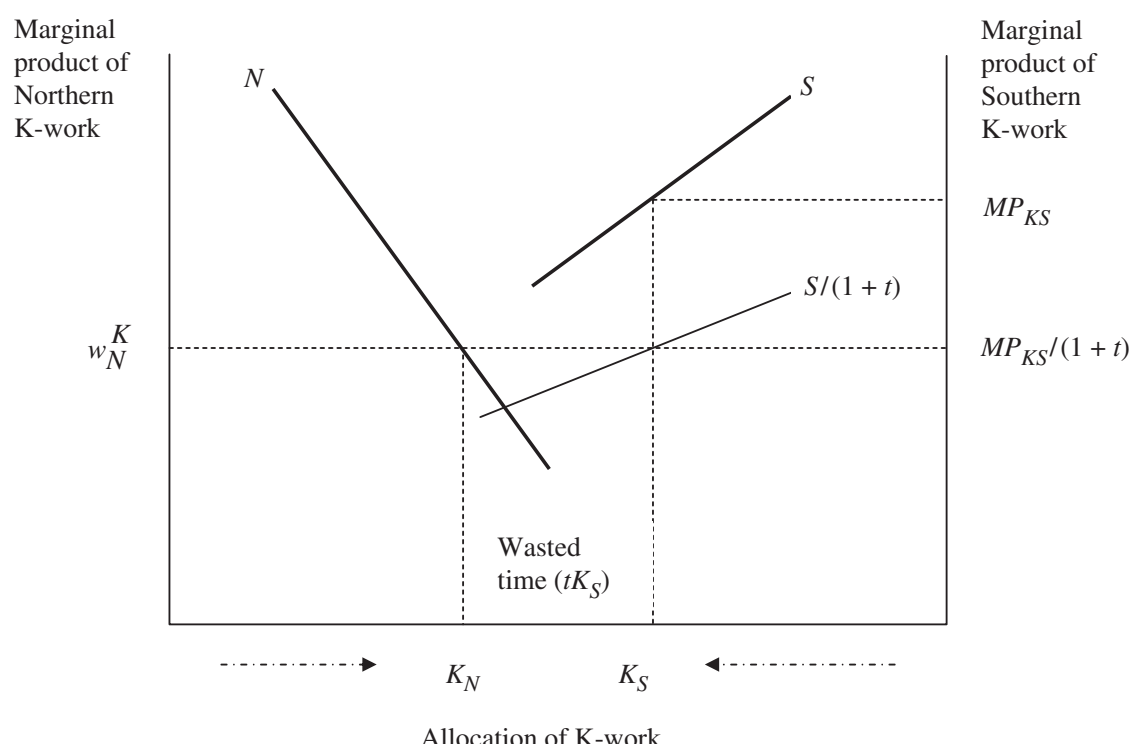

Fig. 1. Equilibrium with given co-operation costs

The key features of the model are illustrated in Fig. 1 (a more formal analysis is available on request). This type of figure, attributed to Mussa (1974), is often used to analyse the effects of factor mobility, both between countries and (in specific-factors models) between sectors. Its horizontal axis shows the division of K-work between the North (measured from the left) and the South (measured from the right), with the segment in the middle, between $K_{N}$ and $K_{S}$, being time wasted on co-operation costs $\left(=t K_{S}\right)$. The lines $N$ and $S$ trace the relationships, in the North and the South respectively, between the marginal physical product of K-work and the amount of K-work done in the region. The line $S /(1+t)$ traces the relationship between $K_{S}$ and the return to K-work in the South, which is its marginal product there, net of co-operation costs (so that this line is a constant proportional distance below $S) .{ }^{6}$ The horizontal broken line through $S /(1+t)$ is the K-worker arbitrage condition, by which the return to K-work in the South must equal the wage of K-workers in the North.

The line $N$ is derived from the A-sector production function, given the fixed number of Northern L-workers: its slope is steeper, the lower is the elasticity of substitution $(\sigma)$ between $\mathrm{K}$-work and L-work. The line $S$, however, since the number of L-workers in the Southern A-sector is not fixed, is a composite relationship, derived from the Southern L-worker arbitrage condition and the

\footnotetext{
${ }^{6}$ The value of the co-operation cost parameter, $t$, determines two features of the figure-horizontally, the ratio of wasted time to effective Southern K-work $\left(t K_{S} / K_{S}=t\right)$, and vertically, the proportional distance between the gross and net $S$ curves: $(S-S /(1+t)) /(S /(1+t))=t$.
} 
demand function. More specifically, the marginal product of Southern K-work depends proximately on $k_{S}$, which in turn depends, via the L-worker arbitrage condition, on $p_{A} / p_{B}$. The relative price $p_{A} / p_{B}$ depends, via the demand function, on the relative outputs of the A-good and the B-good, $Q_{A} / Q_{B}$. This quantity ratio rises with $K_{S}$ because a greater supply of $\mathrm{K}$-work in the South draws more Southern L-workers out of B-production. In short, as $K_{S}$ rises, so does $L_{A S}$ and $Q_{A} / Q_{B}$, which lowers $p_{A} / p_{B}$, raises $k_{S}$, and thus lowers the marginal product of Southern K-work.

The slope of the line $S$ evidently depends on the values of several parameters, but one important determinant is the elasticity of substitution in consumption, $\varepsilon$. The larger the value of this parameter, the shallower is the slope of the line. If $\varepsilon$ were infinite, for example, $p_{A} / p_{B}$ would not change, whatever happened to $Q_{A} / Q_{B}$, and so nor would $k_{S}$ or the marginal product of Southern K-work, making $S$ horizontal. If $\varepsilon$ were small, by contrast, $S$ would be steeply sloped, possibly more so than $N$. However, Fig. 1 is drawn to show $S$ shallower than $N$, on the basis of what seems to be the most plausible combination of parameter values. Because lowerquality goods are reasonable substitutes for state-of-the-art goods, at least in the South, which is the main and perhaps the only market for B-goods, $\varepsilon$ is likely to be fairly high. But $\sigma$ (which determines the slope of $\mathrm{N}$ ) is likely to be low: other workers are poor substitutes for K-workers in the production of A-goods, because they lack the know-how needed to create, produce and market state-of-the-art goods.

\section{Effects of falling co-operation costs}

The results of a fall in co-operation costs are not entirely straightforward, because it has two different and potentially offsetting effects. The more obvious, and usually the dominant one, is a 'substitution' effect, whereby the reduction in the amount of time wasted increases the attractiveness of working in the South to K-workers, who therefore do more work there, and less in the North. But there is also an 'efficiency' effect: lower co-operation costs tend to raise the effective world supply of K-workers $\left(K_{S}+K_{N}\right)$, by reducing the amount of time they waste, $t K_{S}$. So more K-work in the South need not imply less K-work in the North. ${ }^{7}$

Because these two effects conflict, a fall in co-operation costs could either increase or decrease wage inequality in the North between K-workers and L-workers (a formal analysis is available on request). The direction of the outcome depends proximately on what happens to $k_{N}$. If the substitution effect dominates, $k_{N}$ falls and so $w_{N}^{K} / w_{N}^{L}$ rises (an increase in inequality). But if the efficiency

\footnotetext{
${ }^{7}$ The efficiency effect is relevant only if the initial equilibrium involved some Southern A-production. If the fall in co-operation costs were from a prohibitive level to a permissive level (initiating Southern A-production), only the substitution effect would matter, and wage inequality within the North would necessarily increase.
} 


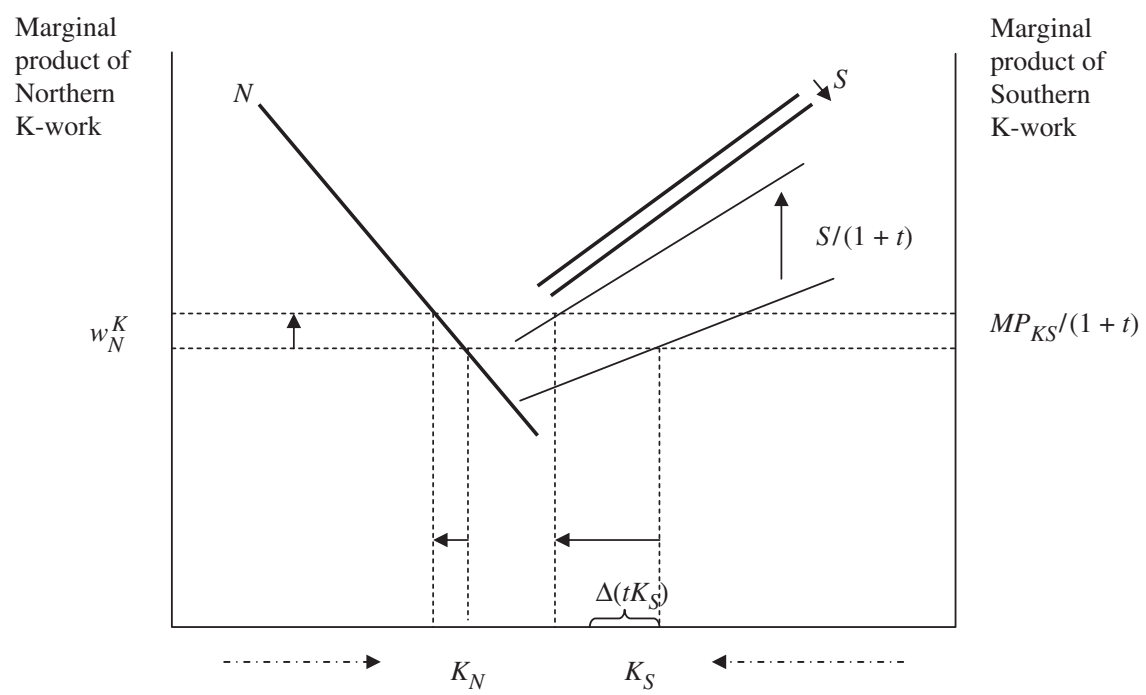

Allocation of K-work

Fig. 2. Effects of reduction of co-operation costs

effect were to pull strongly in the opposite direction, so that the reduced waste of $\mathrm{K}$-worker time led to a rise in K-work both in the South and in the North, $k_{N}$ would rise and $w_{N}^{K} / w_{N}^{L}$ would fall. Such an outcome would require, however, not just a rise in the effective world supply of K-work, but also a world average elasticity of demand for K-work below unity, taking into account both substitution between $\mathrm{K}$-workers and L-workers within the A-sector and substitution between the A-good and the B-good.

Figure 2 shows how a reduction in $t$ tends to cause the line $S /(1+t)$ to shift upwards: a fall in co-operation costs raises the return to K-work in the South, given its marginal product there. This upward shift (which occurs despite a partially offsetting downward shift in the line $S)^{8}$ raises the net return to Southern $\mathrm{K}$-work and thus the wage of K-workers. However, the Northern K-wage rises by less than the upward shift of $S /(1+t)$, because the increased supply of K-work to the South causes downward movement along $S /(1+t)$, to an extent dependent on the slope of the curve.

For reasons mentioned above, we have drawn $S$ with a relatively shallow slope. The outcome is thus that $w_{N}^{K}$ rises as a result of the fall in $t$, which entails also a fall in $K_{N}$ and hence (given $L_{N}$ ) in $k_{N}$, so that wage inequality in the North is increased. In the limiting case of an infinite value of $\varepsilon$, which would make $S$ horizontal and its

\footnotetext{
${ }^{8} \mathrm{~S}$ shifts downward because the initial effects of lower co-operation costs are to raise production of the A-good, lower its relative price and induce more Southern workers to work in the B-sector. Given $K_{S}$, the marginal product of K-work in the South therefore falls.
} 
position fixed, this outcome would be guaranteed (because, with no change in $p_{A} / p_{B}$ and hence in $k_{S}$, it is clear from the K-worker arbitrage condition that a fall in $t$ would raise $w_{N}^{K}$ and lower $k_{N}$ ). The figure also shows, though, that the outcome could be in the opposite direction: if $S /(1+t)$ were steeply sloped and did not shift upwards much, because $\varepsilon$ was low, the net return to K-work in the South would fall, and with it the wage of K-workers in the North, both absolutely and relative to Northern L-workers (because $K_{N}$ and $k_{N}$ would rise).

Turning to wage inequality between Northern and Southern L-workers, the impact of a fall in co-operation costs can be inferred straightforwardly from inspection of the K-worker arbitrage condition (eq. (7)). A reduction in the value of $t$ evidently lowers the ratio $(>1)$ of the marginal productivity of $\mathrm{K}$-work in the South to the marginal productivity of K-work in the North. It must thus correspondingly raise the ratio $(<1)$ of the marginal productivity of L-work (in the A-sector) in the South to the marginal productivity of L-work in the North (since the production function and the price of the A-good are the same in both regions). Since it is this marginal productivity ratio which governs the relative wages of Northern and Southern L-workers (eq. (6)), wage inequality between these two groups is bound to fall.

In addition to reducing the relative wage advantage of Northern L-workers over Southern L-workers, reduction of co-operation costs must raise the absolute real wage of Southern L-workers, since their wage in terms of the B-good does not alter, and the relative price of the B-good rises. In general, moreover, the absolute real wage of Northern L-workers is reduced. This is because the decline in $k_{N}$ reduces their marginal physical productivity and hence their wage in terms of their own product, with the decline in their consumption wage being reinforced by the fall in the price of their own product (the A-good) relative to the B-good. Even in the unusual case in which $k_{N}$ rises, the real consumption wage of Northern L-workers is likely to decline as a result of the relative price change (which tends to be large in this case).

Although our focus is on falling co-operation costs, it is of interest also to consider the impact of a rise in $L_{S} / L_{N}$ as a result of faster Southern population growth. One effect is to raise $w_{N}^{L} / w_{S}^{L}$, pulling in the opposite direction to falling co-operation costs. This happens because the increased supply of Southern labour raises output of the B-good, driving down its relative price and hence encouraging Southern L-workers to move into the A-sector, where their increased numbers, given the supply of K-work to the South, lower $k_{S}$ and the marginal productivity of Southern L-work, relative to that of Northern L-work. This tendency is damped, however, by an expanded supply of K-work to the South, induced by the fall in $k_{S}$ (which raises the marginal productivity of Southern K-work, relative to Northern $\mathrm{K}$-work). The supply of K-work to the North is thus reduced, and so $k_{N}$ falls, increasing wage inequality in the North, which reinforces the (usual) effect of falling co-operation costs.

To summarize, our theoretical model predicts that a fall in co-operation costs will have two effects on wage inequalities. It will usually tend to widen the wage gap 
within developed countries between highly-skilled and less-skilled workers, and it will tend to narrow the gap between developed and developing countries in the wages of less-skilled workers. The rest of the paper is devoted to testing these predictions.

\section{Empirical evidence: wage inequality in the North}

In this section we estimate the contribution of increasing international business travel and communication to rising wage inequality in one large Northern country, the United States. We first show that both the amount of business travel to developing countries and the relative earnings of international business travellers rose during the 1990s. We then show that, on plausible assumptions, this rise in travel can account for a substantial fraction of the observed increase in inequality in the upper half of the US income distribution.

\subsection{Amount of international business travel}

Information on outgoing international business travel from the United States between 1986 and 1997 is shown in Table 1. The source is the International Air Passenger Survey (IAPS), a monthly survey of travel to and from the United States, carried out by a branch of the US Department of Commerce. ${ }^{9}$ Three series are shown: the total number of international business travellers, the average amount of time spent outside the US on each international business trip, and the proportion of countries visited which were in the South (non-OECD). An estimate of the total amount of time spent by business travellers in Southern countries can be obtained by multiplying these three series together, assuming that each traveller makes just one trip during the year and that trips to non-OECD destinations are of similar duration to those to OECD countries. (The IAPS does not contain information on the average number of international business trips per year made by international business travellers. ${ }^{10}$ Nor does it contain separate data on the average amount of time spent in OECD and non-OECD destinations.)

\footnotetext{
${ }^{9}$ Although the IAPS has been carried out since the early 1980s, we show data for 1986, 1990 and 1997 only. The reason is that data from the IAPS, other than the most basic, must be purchased.

${ }^{10}$ Separate evidence from the American Travel Survey (ATS), a survey of approximately 80,000 US households carried out by the US Bureau of Transportation Statistics, suggests that US residents made approximately 6.6 million international business trips in 1995 (see Anderson, 2002). The similarity between this figure and the IAPS estimate of the number of international business travellers in 1997 suggests that the average number of international business trips per international business traveller was close to unity in those years. It may have been higher in earlier years, in which case the results in Table 1 would overestimate the rise in the amount of international business travel over the period, but this seems unlikely: evidence from the IAPS (not shown) shows that the average number of all international trips (including pleasure as well as business trips) made per year by international business travellers rose from 4.4 in 1990 to 5.7 in 1997. If the average number of international business trips per traveller in fact rose over the period, our results would underestimate the rise in the amount of international business travel, and its contribution to the rise in US wage inequality.
} 
Table 1 International business travel from the United States, 1986-97

\begin{tabular}{lccc}
\hline & 1986 & 1990 & 1997 \\
\hline International business travellers (000) & 4,813 & 5,597 & 7,924 \\
Nights spent outside the US (mean per trip) & 16.3 & 14.9 & 12.5 \\
Non-OECD countries visited (\% of total countries visited) & 50.9 & 49.9 & 61.5 \\
Nights spent in non-OECD countries on business trips (000) & 39,932 & 41,614 & 60,916 \\
- equivalent workers (000) & 160 & 166 & 244 \\
-proportion of US employment (\%) & 0.15 & 0.14 & 0.19 \\
\hline
\end{tabular}

Notes: International business travellers are US residents who make at least one trip by air during the year to a foreign country for either business or convention purposes. The number of equivalent workers is obtained by dividing the total number of nights by 250 (a rough estimate of the average number of working days in a year).

Source: IAPS.

The number of international business travellers rose by two-thirds between 1986 and 1997. There was also an increase in the proportion of visits to Southern countries between 1990 and 1997, but a fall in the average amount of time spent outside the US per business trip, both in 1986-90 and in 1990-97. The estimated total amount of time spent on business trips to Southern countries rose only slightly between 1986 and 1990, but increased by nearly 50\% between 1990 and 1997.

It is possible that the data in Table 1 over-estimate the total amount of time supplied by US K-workers to the South, because they include travel to buy and sell goods without significant co-operation in production or marketing. We do not have information on the precise reasons why people travel on business, but information on the occupations of travellers is consistent with a high level of technical and managerial input, as distinct from simply buying or selling. In the 1997 International Air Passenger Survey, for example, 40\% of overseas business travellers from the US classify their jobs as 'professional/technical', and $51 \%$ as 'managerial/executive', while less than $2 \%$ classify themselves as 'clerical/sales'. We also know from the American Travel Survey that in 1995 only $5 \%$ of all business trips were to sales conventions (Anderson, 2002). ${ }^{11}$

It is more likely that the data on travel in Table 1 greatly underestimate the total amount of time supplied by US K-workers to the South. They omit time supplied via telecommunication, as well as time spent on preparation for and follow-up to Southern travel and telecommunication by both travellers and other K-workers. To allow roughly for this underestimation we assume that for travellers time spent abroad is a quarter of the total time they spend on South-related activities and that

\footnotetext{
${ }^{11}$ The case-study evidence cited in footnote 1 tends to confirm that much of the travel connected with trade in types of goods that account for a high share of Southern exports has a co-operative purpose-as is true also for Northern exports of components for use in production of Southern exports.
} 
non-travelling K-workers contribute as much time as travellers. The total amount of time supplied to Southern countries by US K-workers is thus assumed to be eight times that spent on travel to the South, implying that it grew from 1.3 million worker-years in 1986 to 1.9 million in 1997, or from $1.2 \%$ to $1.5 \%$ of total US employment. The proportional rise may still be underestimated, since advances in information and communication technologies probably raised the ratio of the total amount of time spent on South-related activities to time spent travelling.

\subsection{Relative wages of international business travellers}

Table 2 shows estimates of the relative wages of international business travellers. It compares their mean household income (the only income measure collected by the IAPS) with the mean income of all US households, obtained from the March Current Population Survey (CPS) of the US Bureau of the Census. We control for differences in age by comparing the travellers with all households whose householder is in the same age group, and show figures separately for three age groups: 25-34, 35-44, and 45-54. The mean household incomes of international business travellers in all age groups are roughly double those of all households, and in all age groups the size of this income differential rose between 1986 and 1997.

There are of course many possible reasons why the household incomes of international business travellers are higher than those of other households. The results in Table 2 do not control for any differences between international business travellers and the US population in household composition. Nor do they control

Table 2 Incomes of business travellers in the United States, 1986-97 (\$000)

\begin{tabular}{lccc}
\hline & 1986 & 1990 & 1997 \\
\hline Ages 25-34 & & & \\
International business travellers & 57.0 & 73.8 & 97.6 \\
All households & 29.3 & 34.5 & 45.1 \\
-ratio & 1.95 & 2.14 & 2.16 \\
Ages 35-44 & & & \\
International business travellers & 75.1 & 97.4 & 135.6 \\
All households & 37.7 & 45.1 & 2.1 .38 \\
-ratio & 1.99 & 2.16 & 158.8 \\
Ages 45-54 & 84.2 & 108.0 & 65.3 \\
International business travellers & 41.1 & 50.0 & 2.43 \\
All households & 2.05 & 2.16 & \\
-ratio & & & \\
\hline
\end{tabular}

Notes: The results are based on an adjustment factor of 1.5 for top-coded incomes in the IAPS. The top-coded income group is \$70,000 and above in 1986 (48\% of travellers), \$110,000 and above in 1990 (31\% of travellers), and \$200,000 and above in 1997 (20\% of travellers).

Source: IAPS. 
for the fact that business travellers typically have higher levels of education and experience than other workers. However, results in Anderson (2002), based on more detailed household survey data for a single year (1995), show that the incomes of international business travellers remain significantly higher even after controlling for household composition, education, experience and other demographic characteristics (and that this differential is unlikely to reflect simply compensation for the disutility of travel).

\subsection{Impact on US wage inequality}

To quantify the effect on wage inequality of the estimated increase in time supplied by US K-workers to the South, we use eq. (5) - the inverse relationship between the wage of K-workers relative to Northern L-workers $\left(w_{N}^{K} / w_{N}^{L}\right)$ and the Northern supply of K-work relative to L-work $\left(k_{N}\right)$. This relationship depends on the elasticity of substitution between $\mathrm{K}$-work and L-work $(\sigma)$, about whose size it is necessary to make some assumption. To perform the relevant calculation, it is also necessary to make an assumption about the share of $\mathrm{K}$-workers in the Northern labour force, $\kappa \equiv K /\left(K+L_{N}\right) \equiv K / E$. This is because our data cover only K-work on the South and omit K-work on the North (which is probably the large majority).

Given a value for $\kappa$, we can derive $k_{N}$ from our estimate of the amount of K-work on the South as

$$
k_{N}=\frac{K_{N}}{L_{N}}=\frac{K-K_{S}(1+t)}{E-K}=\frac{\kappa-\kappa_{S}}{1-\kappa},
$$

where $\kappa_{S} \equiv K_{S}(1+t) / E$. Similarly, given that the average wage of all Northern workers $\left(w_{E}\right)$ can be written as

$$
w_{E}=\kappa w_{K}+(1-\kappa) w_{L},
$$

we can derive the wage of all K-workers relative to Northern L-workers from our data on the wage of international business travellers, $w_{T}$, as

$$
\frac{w_{K}}{w_{L}}=\frac{w_{T}-\kappa w_{T}}{w_{E}-\kappa w_{T}}
$$

assuming that all international business travellers are K-workers, so that $w_{T}=w_{K}$.

Panel A of Table 3, based on equations (10) and (12) and the data in Tables 1 and 2, shows the changes in the relative supply of K-workers $\left(k_{N}\right)$ and the relative wage of K-workers $\left(w_{N}^{K} / w_{N}^{L}\right)$ in the US under three alternative assumptions about the value of $\kappa$. Thus for instance, if K-workers were $10 \%$ of the Northern labour force $(\kappa=0.1)$, the estimated rise in $\kappa_{S}$ (K-work on the South as a share of 
Table 3 Impact on US wage inequality

\begin{tabular}{|c|c|c|c|c|c|c|}
\hline & \multicolumn{3}{|c|}{ 1990-97 } & \multicolumn{3}{|c|}{ 1986-97 } \\
\hline \multicolumn{7}{|c|}{ A. Inferred changes in $k_{N}$ and $w_{N}^{K} / w_{N}^{L}$ (\% per year) } \\
\hline$\kappa$ & $k_{N}$ & & & $k_{N}$ & \multicolumn{2}{|c|}{$w_{N}^{K} / w_{N}^{L}$} \\
\hline 0.05 & -1.5 & & & -0.8 & \multicolumn{2}{|c|}{1.8} \\
\hline 0.1 & -0.6 & & & -0.4 & \multicolumn{2}{|c|}{2.1} \\
\hline 0.2 & -0.3 & & & -0.2 & \multicolumn{2}{|c|}{2.9} \\
\hline \multicolumn{7}{|c|}{ B. Contribution of inferred fall in $k_{N}$ to inferred rise in $w_{N}^{K} / w_{N}^{L}(\%)$} \\
\hline & \multicolumn{3}{|c|}{$\sigma$} & \multicolumn{3}{|c|}{$\sigma$} \\
\hline$\kappa$ & 0.5 & 1 & 2 & 0.5 & 1 & 2 \\
\hline 0.05 & 191 & 95 & 48 & 93 & 46 & 23 \\
\hline 0.1 & 71 & 35 & 18 & 34 & 17 & 9 \\
\hline 0.2 & 23 & 12 & 6 & 12 & 6 & 3 \\
\hline
\end{tabular}

total US employment) from $1.2 \%$ to $1.5 \%$ between 1986 and 1997 would have caused $k_{N}$ to fall by $0.4 \%$ per year. Over the same period, the rise of $5.5 \%$ per year in $w_{T}$ and $3.8 \%$ per year in $w_{E}$ (using the values for the 35-44 age group) would have translated into a rise of $2.1 \%$ per year in $w_{N}^{K} / w_{N}^{L}$. If $\kappa$ were assumed to be smaller, the fall in $k_{N}$ would be larger and the rise in $w_{N}^{K} / w_{N}^{L}$ smaller, and vice versa. If $\kappa$ were assumed to have risen over the period, the rate of decline in $k_{N}$ would be smaller and the rise in $w_{N}^{K} / w_{N}^{L}$ would be larger.

Panel B of Table 3, based on eq. (5), shows the percentage of the inferred rise in $w_{N}^{K} / w_{N}^{L}$ which is explained by the inferred fall in $k_{N}$. Separate estimates are shown for our alternative assumptions about $\kappa$ and for three alternative assumed values of $\sigma(0.5,1$ and 2). For instance, if $\kappa=0.1$ and $\sigma=1$, the decline of $0.4 \%$ per year in $k_{N}$ during $1986-97$ would have contributed $0.4 \%$ per year of the overall $2.1 \%$ per year inferred rise in $w_{N}^{K} / w_{N}^{L}$ during that period, a share of $17 \%$ (adjusted for rounding errors). Larger assumed values of $\kappa$ and $\sigma$ make these shares smaller, and vice versa. On our best guesses of the values, which are $\kappa=0.1$ and $\sigma=0.5$, the increase in Southern K-work would explain 34\% of the rise in wage inequality between K-workers and L-workers during 1986-97 and 71\% of it during 1990-7.

The results in Table 3 can be used to estimate the contribution of the rise in Southern K-work to the increase in overall inequality in the US. According to the US Census Bureau, the ratio of mean household income in the top household quintile to that in the middle quintile rose from 2.93 in 1990 to 3.30 in 1997. Assuming all $\mathrm{K}$-workers to be in the top quintile, our best guesses of the values of $\kappa(0.1)$ and $\sigma(0.5)$ imply that about one-third of this increase in inequality could be explained by the increasing share of their time that US K-workers spent 
on co-operation with Southern rather than Northern L-workers. ${ }^{12}$ This number could be made larger or smaller by altering the various assumptions on which it is based, but it suggests to us that falling co-operation costs may well account for a substantial proportion of the recent rise in upper-tail wage inequality both in the US and in other developed countries.

\section{Empirical evidence: North-South wage inequality}

Lack of suitable data precludes a time-series test of the prediction that increasing co-operation between K-workers and Southern L-workers narrows the gap in wages between Northern and Southern L-workers. Instead, we do a cross-section test, treating the South not as one country (as in our basic model) but, more realistically, as many different countries. Our hypothesis is that Southern countries where co-operation costs are lower tend to have higher wages. We test this hypothesis in two stages, first asking whether lower co-operation costs are associated with larger amounts of inward business travel and then asking whether more inward business travel is associated with higher wages. Both stages of the test support the hypothesis.

\subsection{Method}

Equation (6) implies that the wage of L-workers in any one Southern country $i$ relative to the L-worker wage in the North (denoting this ratio by $w_{i}^{L}$ ) is a positive function of the effective amount of K-worker time supplied to that country, relative to L-worker employment in the A-sector $\left(k_{i}=K_{S i} / L_{A S i}\right)$. The wage in the Southern country will of course depend also on other things, so we can rewrite the equation for purposes of estimation as

$$
\ln \left(w_{i}^{L}\right)=\alpha+\beta \ln k_{i}+\chi \bar{z}_{i}+v_{i}
$$

where $\bar{z}_{i}$ is a set of other observed influences on $w_{i}^{L}$, and $v_{i}$ includes unobserved influences. Eq. (7), the K-worker arbitrage condition, in turn implies that $k_{i}$ is a negative function of the level of co-operation costs in the country concerned $\left(t_{i}\right)$, and can be rewritten as

$$
\ln \left(k_{i}\right)=\delta-\phi \bar{t}_{i}+\varepsilon_{i}
$$

\footnotetext{
${ }^{12}$ The decline in $k_{N}$ caused by the rise in Southern K-work accounts for $71 \%$ of the $1.8 \%$ p.a. rise in $w_{N}^{K} / w_{N}^{L}$, i.e $1.3 \%$ p.a. Given $\kappa=0.1$, we assume that K-workers make up half of the top income quintile, $\mathrm{Q} 1$, and that the average income of $\mathrm{L}$-workers is close to the average of the middle quintile, Q3, so that this relative wage rise can explain $0.6 \%$ p.a. (half of $1.3 \%$ ) or about one third of the overall $1.7 \%$ p.a. rise of the Q1/Q3 income ratio.
} 
where $\bar{t}_{i}$ is a set of proxy measures of co-operation costs in Southern country $i$, and $\varepsilon_{i}$ includes unobserved influences on $k_{i}$ plus any short-term deviations from arbitrage.

Our approach is first to estimate eq. (14) using the widest available set of proxies for co-operation costs and suitable instruments, and then to use the predicted values from this regression as an instrument for $k_{i}$ in eq. (13). This avoids the problem (with ordinary least squares) of potential correlation between $k_{i}$ and $v_{i}$. It also allows us to separate out the effects of variables which affect wages both via their effect on $k_{i}$ and via other channels. The approach requires that at least some of the proxies for co-operation costs affect wages only through their effect on $k_{i}$, and can therefore be excluded from the set of variables $\bar{z}_{i}$.

\subsection{Data}

We use four proxies for co-operation costs in each country: the quality of its institutions, as measured by the rule of law index of Kaufmann et al. (2003); its minimum distance from the US, EU, or Japan; the minimum time difference between it and the US, EU, or Japan; and the proportion of its population speaking a Western European language. All are likely to affect the costs of business travel and communication between that country and the North. In addition, geographical distance, time difference and language spoken can reasonably be assumed to be unaffected by any unobserved shocks to wages and productivity, while valid instruments are available for institutional quality: either a country's distance from the equator (used by Hall and Jones, 1999) or the mortality rate of early European settlers (as in Acemoglu et al., 2001).

Both the quality of a country's institutions and its distance from the EU, Japan, or US are likely to affect wages and productivity through various channels, of which their effect on inflows of K-workers from abroad is only one, and must therefore also be included in the set of control variables $\bar{z}_{i}$. However, after controlling for geographical distances, one can plausibly assume that time differences from the EU, US, or Japan have no other effects on wages and productivity. Similarly, once we control for institutional quality, with which it will be correlated, it is plausible to assume that the proportion of the population speaking a European language has no other effects on wages and productivity. These latter variables can therefore be excluded from $\bar{z}_{i}$.

The proportion of the population speaking a European language has been used by others as an instrument for institutional quality (e.g. Hall and Jones, 1999; Rodrik et al., 2004). The reasoning is that countries favoured by Europeans for colonization during the 18th and 19th centuries-which as a result have larger fractions of their populations speaking a European language today-were also those in which Europeans had most incentive to establish high-quality institutions. Although this may account for the correlation between language and institutional quality, the former would not be an appropriate instrument for 
Table 4 Intra-South wage inequality: list of variables

\begin{tabular}{|c|c|c|c|}
\hline Variable name & Variable description & Mean & Std. dev. \\
\hline PCY & Log GNP per capita, US\$ in 1996 & 7.093 & 1.452 \\
\hline DIST & $\begin{array}{l}\text { Minimum distance from New York, London } \\
\text { or Tokyo }(\mathrm{km}), \log \end{array}$ & 8.492 & 0.416 \\
\hline LANG & $\begin{array}{l}\text { Proportion of population speaking English, French, } \\
\text { German, Spanish or Portuguese }\end{array}$ & 0.366 & 0.425 \\
\hline TIME & $\begin{array}{l}\text { Minimum time difference with New York, London } \\
\text { or Tokyo (hours) }\end{array}$ & 1.343 & 1.194 \\
\hline INST & $\begin{array}{l}\text { Rule of law index in } 1998 \text { constructed by } \\
\text { Kaufmann et al. (2003) (z-score) }\end{array}$ & -0.253 & 0.864 \\
\hline KL & $\begin{array}{l}\text { Incoming business travel, log person-years per } \\
\text { million inhabitants, } 1995 \text { or closest year }\end{array}$ & 4.938 & 2.020 \\
\hline POP & Population in $1996, \log$ & 16.329 & 1.553 \\
\hline AREA & Land area, $\log$ & 16.921 & 2.120 \\
\hline DEQTR & Distance from the equator, $0-1$ scale & 0.162 & 0.112 \\
\hline SMR & European settler mortality per thousand, log & 4.606 & 1.171 \\
\hline
\end{tabular}

Notes: Descriptive statistics are calculated from the sample of countries for which data on settler mortality rates are available, as well as all other variables $(n=51)$.

the latter if language affected wages and productivity directly, through its impact on inflows of business travel and communication.

We measure $k_{i}$ from data on the number of incoming business and professional visits, published by the World Tourism Organization (2000). A business trip is defined as a visit by a foreign national for the purpose of business or attending a convention/conference, where the intention is to stay no longer than a month. We convert the data on visits into the number of equivalent workers, by dividing the number of incoming business visits by 25 (assuming the average length of a business trip to be ten working days and 250 working days in an average working year). This total is then expressed as a proportion of the population of the Southern country. ${ }^{13}$ GNP per capita, measured at official market exchange rates, is used as a proxy for $w_{i}$. Table 4 provides acronyms and summary statistics for all these variables.

There is a significant positive correlation between the amount of inward business travel developing countries receive (measured by World Tourism Organization data) and the amount of net foreign direct investment they receive (measured from balance of payments statistics). ${ }^{14}$ That there should be such a correlation is

\footnotetext{
${ }^{13}$ The limitations of these data are discussed in more detail in Anderson (2004). The most serious concern is that they do not include $\mathrm{K}$-worker services supplied via telecommunication, causing the estimated value of $\beta$ to be biased downward. However, there are a priori grounds for thinking that this bias will be small, most notably because there seems to be little substitution between travel and telecommunication (Gaspar and Glaeser, 1998).

${ }^{14}$ With both variables divided by population and logged, the correlation $\left(\mathrm{R}^{2}\right)$ is 0.45 for the larger sample used in our paper and 0.39 for the smaller sample.
} 
Table 5 Intra-South wage inequality: IV regression results

\begin{tabular}{|c|c|c|c|c|}
\hline $\begin{array}{l}\text { Dependent variable: } \\
\text { Instrument for INST: }\end{array}$ & $\begin{array}{c}1 \\
\text { KL } \\
\text { DEQTR }\end{array}$ & $\begin{array}{c}2 \\
\text { PCY } \\
\text { DEQTR }\end{array}$ & $\begin{array}{c}3 \\
\text { KL } \\
\text { SMR }\end{array}$ & $\begin{array}{l}4 \\
\text { PCY } \\
\text { SMR }\end{array}$ \\
\hline DIST & $\begin{array}{c}-0.143 \\
0.07\end{array}$ & $\begin{array}{c}-0.016 \\
0.90\end{array}$ & $\begin{array}{c}-0.067 \\
0.65\end{array}$ & $\begin{array}{l}0.022 \\
0.88\end{array}$ \\
\hline LANG & $\begin{array}{c}-0.110 \\
0.20\end{array}$ & - & $\begin{array}{l}0.076 \\
0.51\end{array}$ & - \\
\hline TIME & $\begin{array}{c}-0.191 \\
0.02\end{array}$ & - & $\begin{array}{c}-0.275 \\
0.04\end{array}$ & - \\
\hline INST & $\begin{array}{l}0.723 \\
0.00\end{array}$ & $\begin{array}{l}0.702 \\
0.01\end{array}$ & $\begin{array}{l}0.613 \\
0.00\end{array}$ & $\begin{array}{l}0.551 \\
0.08\end{array}$ \\
\hline KL & - & $\begin{array}{l}0.477 \\
0.28\end{array}$ & - & $\begin{array}{l}0.974 \\
0.04\end{array}$ \\
\hline $\mathrm{R}^{2}$ & 0.67 & 0.69 & 0.67 & 0.65 \\
\hline Number of countries & 77 & 77 & 49 & 49 \\
\hline
\end{tabular}

Notes: p-values, calculated using standard errors robust to heteroscedasticity, are shown below each coefficient. All regressions satisfy the Shapiro-Wilk normality test (do not reject the null hypothesis that the residuals are normally distributed), once four outliers (India, Sudan, South Korea and Sierra Leone) are excluded from the larger sample, and two outliers (El Salvador and Sudan) are excluded from the smaller sample. Regression (4) satisfies the Sargan over-identification test (do not reject the null hypothesis of valid instruments), but regression (2) does not. Regression (4) also satisfies the Hausman test (reject the null hypothesis that OLS estimates are efficient and unbiased). All regressions include a constant and control for country size (POP and AREA).

consistent with our model, because transnational companies are an important institutional device for co-operation (albeit by no means the only device, as was explained in Section 1). What would be irrelevant to our model would be travel within transnationals which had invested overseas for reasons other than gains from co-operative production, such as a scarcity of physical or financial capital in the host country. Case study evidence and casual observation suggest that this is rare, not only for manufacturing but also for, say, mining, which usually relies on frequent inputs of know-how from people from headquarters.

\subsection{Results}

Table 5 shows the results for all non-G7 countries with populations exceeding 100,000 for which there are data on all four proxies for co-operation costs. Two alternative instruments for institutional quality are used: columns (1) and (2) are based on DEQTR, while columns (3) and (4) are based on SMR (which greatly reduces the sample size). What are shown in each column are standardized beta coefficients, permitting the effects of different explanatory variables to be compared in size.

The results of the first stage of the test, where the dependent variable is KL and the explanatory variables are LANG, TIME, DIST, and INST, are in columns (1) and (3). DIST and TIME both have negative effects on KL, while INST has a 
positive effect, all as expected. The effects of INST and TIME are statistically significant at the $5 \%$ level in both cases, but the effect of DIST is statistically significant only in column 1 (at the $10 \%$ level). The largest effect is of INST: those of DIST and TIME are much smaller. Contrary to expectation, the impact of LANG in column 1 is negative, but small and not statistically significant.

The results of the second stage of the test, where the dependent variable is PCY and the explanatory variables are DIST, INST, and KL (using the predicted value of $\mathrm{KL}$ from the first-stage regression as an instrument for $\mathrm{KL}$ ), are in columns (2) and (4). The coefficient of most interest is that on KL, which as expected is positive in both cases. The effect is statistically significant at the $5 \%$ level with the smaller sample (column 4), but not with the larger sample (column 2). However, the more significant result in column (4), using SMR as an instrument for institutional quality, should probably be given greater weight, since the test for over-identifying restrictions is satisfied in this case, whereas with DEQTR it is not. Of the other variables, the effect of INST is also positive, large and statistically significant (at the 5\% level in the larger sample and the $10 \%$ level in the smaller sample). This confirms that institutional quality raises wages in Southern countries through other important channels and not only by encouraging K-worker inflows. The effect of DIST, by contrast, is small and not statistically significant in either sample.

To summarize, the results in Table 5 provide support for the hypothesis that wages are higher in developing countries which have lower co-operation costs and as a result get larger inflows of business travel and communication. Further tests described in Anderson (2004) show that this result is robust to alternative definitions of the South, measurement of GNP per capita at PPP exchange rates, and the inclusion of additional control variables. Moreover, the effect is large enough to be of interest to policy-makers: even the lower of the two estimates in Table 5 implies that a one-standard-deviation increase in inward business travel could roughly double a developing country's per capita income. ${ }^{15}$

\section{Conclusions}

This paper has explored the effects on wage inequalities of the increasing extent to which highly-skilled workers who live in the North have become involved in production in the South, as a result of improvements in travel and communications facilities which reduce the cost of co-operation with Southern workers. These effects are encapsulated in a model which treats highly-skilled workers as a semimobile factor, whose services cost more in developing than in developed countries because of the extra time it takes them to go and to work there. Reduction of the amount of time wasted - a fall in co-operation costs—-shrinks the North-South gap

\footnotetext{
${ }^{15}$ The standard deviation of PCY in the larger sample is 1.46. A one standard deviation increase in KL therefore leads to an increase in PCY of $0.48 \times 1.46=0.70 \log$ points, or $100 \%$.
} 
in the wages of less-skilled workers, but widens (usually) the wage gap within the North between highly-skilled and less-skilled workers.

Our empirical tests give support to the qualitative predictions of this model about the effects of greater mobility of highly-skilled workers. The tests also suggest that the impact on wage inequalities is quantitatively important. The increasing extent to which highly-skilled US workers allocated their time to work on developing countries, rather than on the domestic economy, could plausibly have accounted for one-third of the overall rise in inequality in the top half of the US income distribution in the 1990s. Moreover, developing countries whose institutions and geography make their co-operation costs lower are more attractive to Northern highly-skilled workers and as a result have substantially higher wages, relative to wages in the North, than developing countries where co-operation with local workers is more costly.

There is clearly much scope for further empirical testing of the model. But the model itself could be extended in a number of directions. One is include elements of the H-O approach, in which reduction of transport costs rather than co-operation costs is the driving force. Wood (2002) divides our single 'less-skilled' category between medium-skilled and unskilled workers and our single A-good into many A-goods of varying medium/unskilled labour intensity, so that reduction of transport costs alters the relative wages of medium-skilled and unskilled workers in the North and the South in accordance with $\mathrm{H}-\mathrm{O}$ principles. This combined model can account for some apparent effects of globalization on wage inequalities which cannot be explained by either our model or a $\mathrm{H}-\mathrm{O}$ model on its own, including falling relative wages of unskilled workers in low-income countries.

Another subject for further investigation is the supply of highly-skilled workers, which we have taken as given. Like the South (in Section 5 of this paper), the North consists of a number of different countries, in each of which some part of the world's stock of highly-skilled workers resides. The membership of this group is not fixed: if a Southern country acquired a sufficiently large number of highlyskilled residents, it would join the North. This could happen through migration, as with the European colonization of North America, or through learning by natives, as in the case of Japan. In particular, our model could be extended to include the possibility that Southern workers, in some circumstances, learn from the Northern highly-skilled workers with whom they co-operate in production.

\section{Acknowledgements}

Anderson and Wood were funded by awards R000236878 and R000429834260 from the UK Economic and Social Research Council. We are grateful for helpful comments from referees, at seminars at the Universities of Nottingham and Warwick and the LSE, and at conferences of the OECD Development Centre, the International Economic Study Group, and the TSER. 


\section{References}

Acemoglu, D., Johnson, S., and Robinson, J. (2001) The colonial origins of comparative development: an empirical investigation, American Economic Review, 91, 1369-401.

Anderson, E. (2002) Skilled worker mobility and wage inequality, Ch. 2 of D. Phil. thesis, Institute of Development Studies, University of Sussex.

Anderson, E. (2004) Skilled worker mobility and international inequality, mimeo, Overseas Development Institute, London.

Anderson, E. (2005) Openness and inequality in developing countries: a review of theory and recent evidence, World Development, 33, 1045-63.

Arndt, S. and Kierzkowski, H. (2001) Fragmentation: New Production Patterns in the World Economy, Oxford University Press, Oxford.

Bernstein, J. and Mishel, L. (1997) Has wage inequality stopped growing?, Monthly Labor Review, December, 3-16.

Cline, W. (1997) Trade and Income Distribution, Institute for International Economics, Washington DC.

Dolan, C. and Humphrey, J. (2000) Governance and trade in fresh vegetables: the impact of UK supermarkets on the African horticulture industry, Journal of Development Studies, 37, 147-76.

Feenstra, R. and Hanson, G. (1996) Foreign investment, outsourcing and relative wages, in R. Feenstra, G. Grossman, and D. Irwin (eds), Political Economy of Trade Policy: Essays in Honor of Jagdish Bhagwati, MIT Press, Cambridge, MA.

Frank, R. and Cook, P. (1995) The Winner-Take-All Society, Free Press, New York.

Gaspar, J. and Glaeser, E. (1998) Information technology and the future of cities, Journal of Urban Economics, 43, 136-56.

Gereffi, G. (1999) International trade and industrial upgrading in the apparel commodity chain, Journal of International Economics, 48, 37-70.

Hall, R. and Jones, C. (1999) Why do some countries produce so much more output than others?, Quarterly Journal of Economics, 114, 83-116.

Harhoff, D. (1999) Comment on James R. Markusen. Global investment liberalization: effects on labor and the location/agglomeration of high-tech activities and production, in H. Siebert (ed.), Globalization and Labor, Mohr Siebeck, Tübingen.

Harris, R. (1995) Trade and communications costs, Canadian Journal of Economics, 28 (special issue), 46-75.

Hobday, M. (1995) East Asian latecomer firms: learning the technology of electronics, World Development, 23, 1171-93.

Jones, R. and Kierzkowski, H. (1990) The role of services in production and international trade: a theoretical framework, in R. Jones and A. Krueger (eds), The Political Economy of International Trade, Basil Blackwell, Oxford.

Kaufmann, D., Kraay, A., and Mastruzzi, M. (2003) Governance matters III: governance indicators for 1996-2002, Policy Research Working Paper No. 3106, World Bank, Washington, DC.

Krugman, P. (1979) A model of innovation, technology transfer and the world distribution of income, Journal of Political Economy, 87, 253-66. 
Leamer, E. (1993) Wage effects of a US-Mexican free trade agreement, in P. Garber (ed.), The Mexico-U.S. Free Trade Agreement, MIT Press, Cambridge, MA.

Markusen, J. (2001) Contracts, intellectual property rights, and multinational investment in developing countries, Journal of International Economics, 53, 189-204.

Markusen, J., Melvin, J., Kaempfer, W., and Maskus, K. (1995) International Trade: Theory and Evidence, McGraw-Hill, London.

Marshall, A. (1920) Principles of Economics (8th edn), Macmillan, London.

Mussa, M. (1974) Tariffs and the distribution of income: the importance of factor specificity, substitutability and intensity in the short and long run, Journal of Political Economy, 82, 1191-204.

Murphy, K. and Shleifer, A. (1997) Quality and trade, Journal of Development Economics, 53, 1-16.

Rauch, J. and Casella, A. (2003) Overcoming informational barriers to international resource allocation: prices and ties, Economic Journal, 113, 21-42.

Robbins, D. (1996) Evidence on trade and wages in the developing world, Technical Paper No. 119, OECD Development Centre, Paris.

Rodrik, D., Subramanian, A., and Trebbi, F. (2004) Institutions rule: the primacy of institutions over geography and integration in economic development, Journal of Economic Growth, 9, 131-65.

Rosen, S. (1981) The economics of superstars, American Economic Review, 71, 845-58.

Sachs, J. and Shatz, H. (1996) Globalization and the US labor market, American Economic Review, 86, 234-39.

Schmitz, H. and Knorringa, P. (2000) Learning from global buyers, Journal of Development Studies, 37, 177-205.

Wood, A. (1994) North-South Trade, Employment and Inequality: Changing Fortunes in a Skill-Driven World, Clarendon Press, Oxford.

Wood, A. (1997) Openness and wage inequality in developing countries: the Latin American challenge to East Asian conventional wisdom, World Bank Economic Review, 11, 33-57.

Wood, A. (2002) Globalisation and wage inequalities: a synthesis of three theories, Weltwirtschaftliches Archiv, 138, 54-82.

World Bank. (1993) The East Asian Miracle, Oxford University Press, New York.

World Bank. (2003) Global Economic Prospects, World Bank, Washington, DC.

World Tourism Organization. (2000) Compendium of Tourism Statistics: 1994-1998, World Tourism Organization, Madrid. 